\title{
Single nucleotide polymorphism rs5029937 in TNFAIP3 gene is correlated with risk of rheumatoid arthritis
}

\author{
Bahram Pakzad ${ }^{1}$, Farzaneh Yousefisadr ${ }^{1}$, Hadi Karimzadeh ${ }^{1}$, Maryam Mousavi $^{1}$, Elham Noormohamadi $^{1}$, Rasoul Salehi $^{2 *}(\mathbb{D}$ \\ Received: 13 Jul 2020 \\ Published: 31 Mar 2021
}

\begin{abstract}
Background: Rheumatoid arthritis (RA) is a progressive and common autoimmune disease with multifactorial etiology. Several pieces of research show that genetic factors play a major role in the incidence of RA. Several genome-wide association studies (GWAS) have identified the tumor necrosis factor alpha inducible protein 3 (TNFAIP3) genes as one of the candidate loci. The TNFAIP3 gene encoding ubiquitin-editing protein A20 witch restricts B cell survival and prevents autoimmunity. Previous studies have indicated that single nucleotide polymorphisms (SNPs) in the TNFAIP3 gene are correlated with several autoimmune disorders. In the present study, we assessed the possible association between SNP rs5029937 (intronic variant) in the TNFAIP3 gene with RA risk in the Iranian population.

Methods: A case-control study using 50 RA patients and 50 control subjects was undertaken to evaluate rs5029937 (G>T) genotypes using real-time PCR high resolution melting method (HRM). The SPSS22 was used for statistical analyses and the significance level was set at $\mathrm{P}<0.05$.

Results: Logistic regression analysis demonstrates that homozygous TT + heterozygous TG genotypes compared with GG genotype increase the risk of RA (TT+TG vs GG; $\mathrm{P}=0.004, \mathrm{OR}=3.46 ; 95 \% \mathrm{CI}[1.492-8.075]$ ). Also, individuals with allele $\mathrm{T}$ were more frequently affected with RA than subjects with $\mathrm{G}$ allele ( $\mathrm{T}$ vs $\mathrm{G} ; \mathrm{P}=0.004, \mathrm{OR}=2.61 ; 95 \% \mathrm{CI}[1.382-4.919]$ ).

Conclusion: Our findings propose a substantial correlation between rs5029937 $(\mathrm{G}>\mathrm{T})$ polymorphism and RA risk in Iranian population.
\end{abstract}

Keywords: Rheumatoid Arthritis, TNFAIP3 Gene, Single-nucleotide Polymorphism, Autoimmune Disorder, HRM

Conflicts of Interest: None declared

Funding: Isfahan University of Medical Sciences

*This work has been published under CC BY-NC-SA 1.0 license.

Copyright $₫$ Iran University of Medical Sciences

Cite this article as: Pakzad B, Yousefisadr F, Karimzadeh H, Mousavi M, Noormohamadi E, Salehi R. Single nucleotide polymorphism rs5029937 in TNFAIP3 gene is correlated with risk of rheumatoid arthritis. Med J Islam Repub Iran. 2021 (31 Mar);35:42. https://doi.org/10.47176/mjiri.35.42

\section{Introduction}

Rheumatoid arthritis (RA) is an autoimmune disease that causes chronic inflammation and joint damage and eventually swelling and motor disability in the patient's

Corresponding author: Dr Rasoul Salehi, r_salehi@med.mui.ac.ir

1. Department of Internal Medicine, School of Medicine, Isfahan University of Medical Science, Isfahan, Iran

2. Department of Genetics and Molecular Biology, School of Medicine, Isfahan University of Medical Sciences, Isfahan, Iran joints (1). This disease is the most common form of chronic inflammatory arthritis and often leads to joint damage and physical disability. Since RA is a systemic disease, it

$\uparrow$ What is "already known" in this topic:

Studies have shown that TNFAIP3 is fundamental for regulating inflammation by dismissing TNF-induced $N F K B$ responses through tumor necrosis factor receptor (TNFR), TLR, $I L 1 R$ and NOD2. Variations in the TNFAIP3 gene, as a key regulator of inflammatory signaling pathways, seem to dramatically contribute to autoimmunity.

\section{$\rightarrow$ What this article adds:}

Our results demonstrate that combination of TT $+\mathrm{TG}$ compared with the GG genotype in rs5029937 polymorphism increased the risk of disease. On the other hand, individuals with allele T were more frequently affected with RA than subjects with $G$ allele. 
can cause many extra-articular manifestations, some of which include fatigue, subcutaneous nodules, lung involvement, pericarditis, peripheral neuropathy, vasculitis, and hematologic disorders (2). The worldwide prevalence of RA is approximately between $0.5-1 \%$ and its prevalence increases markedly with age $(3,4)$. RA has multifactorial etiology, mirroring as interaction of several inherited and environmental factors are associated with an increased risk for this disease (5). Several lines of evidence show that genetic determinants are critically involved in the incidence of RA. Twin studies showed that $50-60 \%$ of RA onset could be attributed to genetic factors $(6,7)$. Recently with advances in genotyping and sequencing methods, studies reached several loci associated with RA risk. For example, genome-wide association studies (GWAS) reported more than 100 risk loci for RA in European and Asian descents $(8,9)$. Most of these loci are involved in immunological function; interestingly, there is considerable overlap in these loci between RA and other autoimmune disorders (10). In this way, recent genome-wide association studies (GWAS) determined multiple RArelated single nucleotide polymorphisms (SNPs). The most frequent type of variations in the human genome is single nucleotide polymorphism (SNP) that they exist once almost in every 300 nucleotides (11-13). The tumor necrosis factor alpha inducible protein 3 gene (TNFAIP3) is one of the identified candidate loci by several GWAS that conducted to recognize new predisposing genes of the main autoimmune diseases $(14,15)$. TNFAIP3 encodes the cytoplasmatic zinc finger A20 protein that inhibits $N F K B$ activation and TNF-mediated apoptosis (16). Studies in knockout mice show that TNFAIP3 is important for limiting inflammation by terminating TNF-induced $N F K B$ responses through tumor necrosis factor receptor (TNFR), TLR, IL1R and NOD2 (17). Decreased A20 expression predisposes to autoimmunity as is shown in knockout mice, which exhibits elevated numbers of germinal center B cells, autoantibodies and glomerular immunoglobulin deposits $(18,19)$. Variations in the TNFAIP3 gene, as a key regulator of inflammatory signaling pathways, seem to dramatically contribute to autoimmunity (20). In this way, several association studies demonstrated that polymorphisms in this gene are associated with autoimmune disorders including RA (21-23), systemic lupus erythematosus (SLE) $(24,25)$, type 1 diabetes mellitus (26), systemic sclerosis $(27,28)$, Graves' disease (GD) (29), Behcet's disease (BD) (30), and primary Sjogren's syndrome (pSS) (31). One of these functional polymorphisms is rs5029937 $(\mathrm{G}>\mathrm{T})$ that located in intron 2 of TNFAIP3 gene. A meta-analysis study from 10 casecontrol research revealed that rs5029937 polymorphism increased the risk of RA among Caucasians (21). Furthermore previous studies demonstrated that this variant is associated with SLE in Europeans and Asian populations $(24,32)$. In the present study, we assessed the possible association between SNP rs5029937 $(\mathrm{G}>\mathrm{T})$ in the TNFAIP3 gene with RA risk in the Iranian population for the first time.

\section{Methods}

\section{Study population and sample preparation}

In this case-control study, a total of 50 unrelated subjects with RA as a case (mean age: $51.46 \pm 10.10$ ) and unrelated 50 healthy subjects as a control group (mean age: $49.52 \pm 13.85)$ were included in Isfahan city of Iran. Patients were recruited from the Alzahra hospitals. All the RA subjects met the diagnostic criteria published by the American College of Rheumatology (ACR). All persons in control group had no symptoms or any history of RA or other autoimmune diseases. The study participants were interviewed and data on sex, age (at sampling time) and age of onset, body mass index (BMI, calculated as weight [kg] divided by height [m] squared), blood pressure, smoking status, the presence of diabetes mellitus (DM), thyroid disease and family history of RA and other autoimmune disorders were achieved using a organized questionnaire. Also, we recorded laboratory characteristics such as erythrocyte sedimentation rate (ESR), C-reactive protein (CRP), white blood cell (WBC), hemoglobin, platelet count test (PLT), creatinine, blood urea nitrogen (BUN), fasting blood sugar (FBS), high-density lipoprotein (HDL), low-density lipoprotein (LDL), triglyceride (TG), rheumatoid factor (RF). This study was permitted by the university ethics board and all contributors gave written informed consent.

\section{DNA extraction and genotyping of polymorphism}

Approximately, $5 \mathrm{ml}$ of peripheral blood was prepared into ethylenediaminetetraacetic acid (EDTA) anticoagulant tubes from each subjects and stored at $-20^{\circ} \mathrm{C}$ for DNA isolation. Genomic DNA was extracted from $200 \mu \mathrm{L}$ of venous blood samples using GenetBio kit (Korea) consistent with the instruction manual. The purity and concentration of all genomic DNA samples were assessed by agarose gel electrophoresis and spectroscopy at wavelengths of 260 and $280 \mathrm{~nm}$ respectively, and then DNA was stored at $-20{ }^{\circ} \mathrm{C}$ until genotyping by real? time polymerase chain reaction high?resolution melting (HRM) method.

The HRM method was performed to evaluate rs5029937 polymorphism genotypes. HRM was performed using HOT FIREPol EvaGreen HRM Mix (no ROX) HRM PCR kit which contains HOT FIREPol® DNA Polymerase, 5x EvaGreen ${ }^{\circledR}$ HRM buffer, $12.5 \mathrm{mM} \mathrm{MgCl} 2$, dNTPs, Bovine serum albumin (BSA), and EvaGreen dye (Solis BioDyne Estonia). Analysis carried out with Rotor-Gene $6000^{\mathrm{TM}}$ (Corbett Research, Mortlake, New South Wales, Australia). The forward and reverse primer sequences for the 236-bp fragment that spanned the rs5029937 in TNFAIP3 gene were TTTTGCACTTGCCAAAGGAGA and AAAAAGCACCTGGGTGTCTAAA, respectively. The thermal profile of the reaction is as follows: $5 \mathrm{~min}$ denaturation at $95^{\circ} \mathrm{C}, 40$ cycles of $95^{\circ} \mathrm{C}$ for $10 \mathrm{~s}, 60^{\circ} \mathrm{C}$ ${ }^{\circ} \mathrm{C}$ for $30 \mathrm{~s}$ and $72^{\circ} \mathrm{C}$ for $20 \mathrm{~s}$. The melting curve is generated by increasing between $60{ }^{\circ} \mathrm{C}$ and $95{ }^{\circ} \mathrm{C}$ at $0.1^{\circ} \mathrm{C} / \mathrm{s}$. The melting curve was produced by the reduction in fluorescence with the increase in the temperature; and in analysis, nucleotide changes result in different curve patterns. For using sample genotypes in HRM analysis as a stand- 
ard, specific samples (with different curves) were subjected to direct Sanger sequencing and their correct genotypes were determined.

\section{Statistical analyses}

The SPSS 22 (IBM, Armonk, NY: IBM Corp) was used for statistical analyses. The allele and genotype frequencies were tested for Hardy Weinberg equilibrium by the $\chi^{2}$ test. Logistic regression analysis was accomplished to investigate the association between genotypes and RA and calculate specific odds ratios (ORs), 95\% confidential intervals (CIs), and $\mathrm{P}$ values. Other analyses carried out using independent sample t? Chi? square $\left(\chi^{2}\right)$ or Mann-Whitney test. The significance level was set at $P<0.05$.

\section{Results}

\section{Demographic and clinical characteristics}

In order to assess the association among rs5029937 polymorphism with RA risk, we analyzed 100 total subjects in case and control groups; 50 subjects (30 female and 20 male with a mean age of onset: $42.68 \pm 14.01)$ in the case and 58 (27 female and 23 male) healthy subjects in the healthy group. The distributions of selected characteristics of the cases and controls are presented in Table 1. There was no considerable association between case and control group regarding age $(\mathrm{p}=0.334)$ and gender $(\mathrm{p}=0.342)$, representative that matching for these factors was sufficient. However, cases and controls did not contrast on BMI $(p=0.394)$ and systolic blood pressure (SBP) $(p=0.537)$ and diastolic blood pressure (DBP) $(\mathrm{p}=0.918)$. Ten $(20 \%)$ patients had DM while healthy controls did not have DM $(p=0.001)$ and ten $(20 \%)$ patients had a positive family history where controls did not have a history of any autoimmune disease $(\mathrm{p}=0.001)$. Based on laboratory tests, ESR and CRP were meaningfully higher in cases than in healthy controls $(p<0.001)$. Positive RF was detected in 50 $(100 \%)$ patients. Other laboratory factors including WBC, FBS, hemoglobin, creatinine, BUN, PLT, HDL, LDL, and TG were not significantly different between patients and healthy controls $(p>0.05)$. The detailed laboratory characteristics of patients with RA and healthy controls are listed in Table 2.

\section{Genotype and allele distribution}

The analysis demonstrates that the genotype distribution of rs5029937 polymorphism in two groups was in agreement with Hardy-Weinberg equilibrium. The frequency of GG genotype in case and control group was $32 \%$ and $62 \%$ respectively and frequency of TG genotype in case and control group was $60 \%$ and $38 \%$ respectively and finally frequency of TT genotype in case group was $8 \%$ but was not found in control group $(0 \%)$. When we compared the combined genotype, our results demonstrated that the TT + TG compared to the GG genotype increase the risk of RA ( $p=0.004)$ (Table 3). Also, in allele distribution, we found that $\mathrm{T}$ allele has a high frequency in the case group (38\%) compared to the control group (19\%) and this allele (T) is associated with RA risk $(p=0.004)$. In addition, our analysis revealed that the median concentration of ESR

Table 1. Baseline characteristics of RA patients and control subjects participated in the study

\begin{tabular}{|c|c|c|c|}
\hline Characteristics & Patients & Controls & $\mathrm{p}$ \\
\hline Total number & 50 & 50 & \\
\hline Age & $51.46 \pm 10.10$ & $49.52 \pm 13.85$ & 0.334 \\
\hline \multicolumn{4}{|l|}{ Gender n (\%) } \\
\hline Male & $20(40 \%)$ & $23(46 \%)$ & 0.342 \\
\hline Female & $30(60 \%)$ & $27(54 \%)$ & \\
\hline Age of onset & $42.68 \pm 14.01$ & -- & -- \\
\hline BMI & $25.87 \pm 3.85$ & $24.89 \pm 6.98$ & 0.394 \\
\hline SBP & $119.20 \pm 14.19$ & $120.4 \pm 10.49$ & 0.537 \\
\hline DBP & $80.01 \pm 8.08$ & $79.80 \pm 9.68$ & 0.918 \\
\hline Positive family history $\mathrm{n}(\%)$ & $10(20 \%)$ & 0 & 0.001 \\
\hline Diabetes mellitus & $10(20 \%)$ & 0 & 0.001 \\
\hline Thyroid disease & $5(10 \%)$ & 0 & 0.021 \\
\hline Smoker & $5(10 \%)$ & 0 & 0.021 \\
\hline
\end{tabular}

Data are mean \pm SD, or n (\%). ${ }^{*}$ P value $<0.05$. RA: Rheumatoid arthritis; BMI:Body mass index; SBP: Systolic blood pressure; DBP: Diastolic blood pressure.

Table 2. Laboratory characteristics of patients with RA and controls group

\begin{tabular}{|c|c|c|c|}
\hline & Patients (50) & Controls (50) & $\mathrm{p}$ \\
\hline $\operatorname{ESR}(\mathrm{mm} / \mathrm{h})$ & $37.27 \pm 32.21$ & $15.63 \pm 6.93$ & $<0.001^{*}$ \\
\hline $\mathrm{CRP}(\mathrm{mg} / 1)$ & $19.70 \pm 20.20$ & $4.02 \pm 2.43$ & $<0.001 *$ \\
\hline White blood cell $\left(10^{9} / 1\right)$ & $6.83 \pm 2.41$ & $6.84 \pm 1.62$ & 0.981 \\
\hline Hemoglobin & $13.67 \pm 1.62$ & $14.27 \pm 1.55$ & 0.072 \\
\hline $\operatorname{PLT}\left(10^{9} / 1\right)$ & $228.69 \pm 70.64$ & $221.14 \pm 62.82$ & 0.212 \\
\hline Creatinine $(\mathrm{mg} / \mathrm{dL})$ & $0.94 \pm 0.17$ & $0.87 \pm 0.21$ & 0.081 \\
\hline BUN & $16.52 \pm 4.93$ & $15.83 \pm 4.54$ & 0.473 \\
\hline FBS & $96.30 \pm 20.18$ & $98.18 \pm 42.54$ & 0.782 \\
\hline HDL & $50.66 \pm 9.80$ & $47.5 \pm 12.01$ & 0.151 \\
\hline LDL & $106.39 \pm 31.57$ & $106.16 \pm 38.76$ & 0.976 \\
\hline TG & $141.65 \pm 54.78$ & $147.93 \pm 69.81$ & 0.611 \\
\hline Positive RF & $50(100 \%)$ & - & - \\
\hline
\end{tabular}

Data are mean $\pm \mathrm{SD}$, or $\mathrm{n}(\%) . * \mathrm{P}$ value $<0.05 . \mathrm{RA}=$ Rheumatoid arthritis; ESR: Erythrocyte sedimentation rate; CRP: CQ $\mathrm{g}$ reactive protein; BUN: Blood urea nitrogen; PLT: Platelet; HDL: High@density lipoprotein; LDL: Low国ensity lipoprotein; TG: Triglyceride; FBS: Fasting blood sugar; SD: Standard deviation 


\begin{tabular}{|c|c|c|c|c|}
\hline Genotype group & $\begin{array}{c}\text { Patients }(\mathrm{n}=50) \\
\text { N }(\%)\end{array}$ & $\begin{array}{c}\text { Controls }(\mathrm{n}=50) \\
\mathrm{N}(\%)\end{array}$ & $\mathrm{p}$ & OR $(95 \% \mathrm{CI})$ \\
\hline GG & $16(32 \%)$ & $31(62 \%)$ & Reference & \\
\hline $\mathrm{TG}+\mathrm{TT}$ & $34(68 \%)$ & $19(38 \%)$ & 0.004 & $3.46(1.492-8.075)$ \\
\hline \multicolumn{5}{|l|}{ Allele } \\
\hline G & $62(62 \%)$ & $81(81 \%)$ & Reference & \\
\hline $\mathrm{T}$ & $38(38 \%)$ & $19(19 \%)$ & 0.004 & $2.613(1.382-4.919)$ \\
\hline \multicolumn{5}{|l|}{$* \mathrm{P}$ value $<0.05$} \\
\hline \multicolumn{5}{|c|}{ Table 4. Stratification analyzes of the TNFAIP3 polymorphism (rs5029937) in patients. } \\
\hline Genotype group & & $\mathrm{TG}+\mathrm{TT}(\mathrm{n}=34)$ & $\mathrm{GG}(\mathrm{n}=16)$ & $p$ \\
\hline Age of onset & & $42.91 \pm 14.09$ & $42.2 \pm 13.89$ & 0.621 \\
\hline \multicolumn{5}{|l|}{ Sex } \\
\hline Males & & 12 & 8 & 0.061 \\
\hline Females & & 22 & 8 & \\
\hline $\operatorname{ESR}(\mathrm{mm} / \mathrm{h})$ & & $39.29 \pm 28.16$ & $32.9 \pm 22.36$ & $0.033^{*}$ \\
\hline CRP (mg/l) & & $21.68 \pm 21.58$ & $16.89 \pm 16.93$ & $0.022 *$ \\
\hline Creatinine $(\mathrm{mg} / \mathrm{dL})$ & & $0.96 \pm 0.216$ & $0.85 \pm 0.154$ & 0.079 \\
\hline BMI & & $25.37 \pm 2.85$ & $26.17 \pm 3.23$ & 0.237 \\
\hline
\end{tabular}

Data are mean $\pm \mathrm{SD}$, or $\mathrm{n}(\%) .{ }^{*} \mathrm{P}$ value $<0.05$. ESR: Erythrocyte sedimentation rate;

CRP: C?reactive protein; BMI: Body mass index; SD: Standard deviation

and CRP in the patient group is significantly different in genotype stratification $(\mathrm{p}<0.05)$. However, there was no significant correlation between other clinical factors including sex, age, BMI, creatinine and, age of onset with this polymorphism ( $\mathrm{p}>0.05)$ (Table 4$)$.

\section{Discussion}

To the best of our knowledge, this study is the first research in the Iranian population that considers the association amongst TNFAIP3 polymorphism, rs5029937, with the RA risk. The TNFAIP3 encoding ubiquitin-editing protein A20 witch restricts B cell survival and prevents autoimmunity (33). Based on several previous studies, TNFAIP3 gene and their polymorphisms is one of the crucial genetic factors in inflammation and autoimmune disease, especially in RA $(26,27,34,35)$.

In our work, logistic regression analysis demonstrates that combination of TT+TG compared with the GG genotype increases the risk of disease $(\mathrm{OR}=3.46 ; 95 \% \mathrm{CI}$ [1.492-8.075]). On the other hand, individuals with allele $\mathrm{T}$ were more frequently affected with RA than subjects with $\mathrm{G}$ allele $(\mathrm{OR}=2.61 ; 95 \% \mathrm{CI}$ [1.382-4.919]) (Table 3). Our finding was consistent with studies on Caucasian populations. In a meta-analysis performed by Zhang and colleagues in 2017, they assessed correlation among TNFAIP3 gene polymorphism and RA, stratification analysis of ethnicity revealed that in rs5029937 polymorphism, GT+TT vs. GG genotypes increased the risk of RA in total $(\mathrm{p}<0.001, \mathrm{OR}=1.42)$ and specifically in Caucasians $(p=0.004, O R=1.43)$ while there was not association in Asian ethnicity (just 1 study in Korea) $(\mathrm{p}=0.185)$. Furthermore in this meta-analysis study, revealed same results for allele frequency and they demonstrated that $T$ vs. $G$ allele increased risk of RA in Caucasian $(p=0.002$, $\mathrm{OR}=1.43$ ) but not in Asian ethnicity (just 1 study in Korea) $(p=0.168)(36)$. The other met-analysis study on this polymorphism carried out by Shen et al and their results was consistent with Zhang study (22). On the other hand some studies demonstrated association between rs5029937 and SLE in different type of populations. As instance,
Kim et al revealed that $\mathrm{TT}+\mathrm{TG}$ genotypes and $\mathrm{T}$ allele increased risk of SLE in Korean population (25) and Han et al demonstrate same results in Han Chinese population (37). Furthermore in the patient group, we found a significant correlation between ESR and CRP concentration and rs2075876 polymorphism $(\mathrm{p}<0.05)$ (Table 4). The level of these factors indicates levels of inflammation in the body and refers to active disease. This result demonstrates association of risk allele with severity of disease.

The causes for the some inconsistent results may be due to variances in ethnic background. Nevertheless, performing replicative researches in other population is a necessity to validate these results. We believe that our work would further justify the role of the TNFAIP3 gene and rs5029937 variant in RA susceptibility. Finally, in this work, probably, some probable restrictions in the statistical validity of our results including small population size exist, so additional association studies in larger sample size would help to confirm the proposed associations. Also, other polymorphisms that were not included in our study might be involved in determining the risk of RA, thus future studies are necessary.

\section{Conclusion}

In conclusion, our findings propose a substantial correlation between rs5029937 (G>T) polymorphism and RA risk in Iranian population.

\section{Acknowledgments}

We would like to appreciate any support provided by Isfahan University of Medical Sciences.

\section{Ethics}

The study was approved by Isfahan University of Medical Sciences Ethics board (approval number IR.MUI.MED.REC.1397.010) and written informed consent was filled and signed by all participants.

\section{Conflict of Interests}

The authors declare that they have no competing interests. 


\section{References}

1. Smolen J, Aletaha D, McInnes I. Rheumatoid arthritis. Lancet Lond Engl. 2016;388: 2023-2038..

2. MacGregor AJ, Snieder H, Rigby AS, Koskenvuo M, Kaprio J, Aho $\mathrm{K}$, et al. Characterizing the quantitative genetic contribution to rheumatoid arthritis using data from twins. Arthritis Rheum. 2000;43(1):30-7.

3. Dargham SR, Zahirovic S, Hammoudeh M, Al Emadi S, Masri BK, Halabi $\mathrm{H}$, et al. Epidemiology and treatment patterns of rheumatoid arthritis in a large cohort of Arab patients. PloS One. 2018;13(12).

4. Gabriel S, Crowson C. Epidemiology of Risk Factors for, and Possible Causes of Rheumatoid Arthritis. Up to Date. 2018.

5. Deane KD, Demoruelle MK, Kelmenson LB, Kuhn KA, Norris JM, Holers VM. Genetic and environmental risk factors for rheumatoid arthritis. Best Pract. Res.: Clin. Rheumatol. 2017;31(1):3-18.

6. Castro-Santos P, Díaz-Peña R. Genetics of rheumatoid arthritis: a new boost is needed in Latin American populations. Rev Bras Reumatol. 2016;56(2):171-7.

7. Yarwood A, Huizinga TW, Worthington J. The genetics of rheumatoid arthritis: risk and protection in different stages of the evolution of RA. Rheumatology. 2016;55(2):199-209.

8. Okada Y, Eyre S, Suzuki A, Kochi Y, Yamamoto K. Genetics of rheumatoid arthritis: 2018 status. Ann Rheum Dis. 2019;78(4):446-53.

9. Viatte S, Plant D, Raychaudhuri S. Genetics and epigenetics of rheumatoid arthritis. Nat Rev Rheumatol. 2013;9(3):141.

10. Danila MI, Laufer VA, Reynolds RJ, Yan Q, Liu N, Gregersen PK, et al. Dense genotyping of immune-related regions identifies loci for rheumatoid arthritis risk and damage in African Americans. Mol Med. 2017;23(1):177-87.

11. Mosallaei M, Simonian M, Ahangari F, Miraghajani M, Mortazavi D, Salehi AR, et al. Single nucleotide polymorphism rs4648298 in miRNAs hsa-miR21 and hsa-miR590 binding site of COX gene is a strong colorectal cancer determinant. J Gastrointest Oncol. 2018;9(3):448.

12. Simonian M, Mosallayi M, Miraghajani M, Feizi A, Khosravi S, Salehi AR, et al. Single nucleotide polymorphism rs696 in miR449a binding site of NFKBIA gene is correlated with risk of colorectal cancer. Gastroenterol Hepatol Bed Bench. 2018;11(1):48.

13. Simonian M, Mosallaei M, Khosravi S, Salehi R. rs12904 polymorphism in the 3'-untranslated region of ephrin A1 ligand and the risk of sporadic colorectal cancer in the Iranian population. J Cancer Res Ther. 2019;15(1):15.

14. Thomson W, Barton A, Ke X, Eyre S, Hinks A, Bowes J, et al. Rheumatoid arthritis association at 6q23. Nat Genet. 2007;39(12):1431.

15. Xavier RJ, Rioux JD. Genome-wide association studies: a new window into immune-mediated diseases. Nat Rev Immunol. 2008;8(8):631-43.

16. Tiruppathi C, Soni D, Wang D-M, Xue J, Singh V, Thippegowda $\mathrm{PB}$, et al. The transcription factor DREAM represses the deubiquitinase A20 and mediates inflammation. Nat Immunol. 2014;15(3):239-47.

17. Hayden MS, Ghosh S. Regulation of NF- $\kappa B$ by TNF family cytokines. Semin Immunol. 2014;26(3):253-66.

18. Das T, Chen Z, Hendriks RW, Kool M. A20/Tumor Necrosis Factor $\alpha$-Induced Protein 3 in Immune Cells Controls Development of Autoinflammation and Autoimmunity: Lessons from Mouse Models. Front Immunol. 2018;9:104.

19. Tavares RM, Turer EE, Liu CL, Advincula R, Scapini P, Rhee L, et al. The ubiquitin modifying enzyme A20 restricts B cell survival and prevents autoimmunity. Immunity. 2010;33(2):181-91.

20. Vereecke L, Beyaert R, van Loo G. Genetic relationships between A20/TNFAIP3, chronic inflammation and autoimmune disease. Biochem Soc Trans. 2011;39(4):1086-91.

21. Zhang L, Yuan X, Zhou Q, Shi J, Song Z, Quan R, et al. Associations Between TNFAIP3 Gene Polymorphisms and Rheumatoid Arthritis Risk: A Meta-analysis. Arch Med Res. 2017;48(4):386-92.

22. Shen N, Ruan Y, Lu Y, Jiang X, Sun H, Gao G, et al. Three single nucleotide polymorphisms of TNFAIP3 gene increase the risk of rheumatoid arthritis. Oncotarget. 2017;8(13):20784.

23. Zhu L, Wang L, Wang $\mathrm{X}$, Zhou L, Liao $\mathrm{Z}$, $\mathrm{Xu} \mathrm{L}$, et al. Characteristics of A20 gene polymorphisms and clinical significance in patients with rheumatoid arthritis. J Transl Med. 2015;13(1):215
24. Zhang MY, Yang XK, Pan HF, Ye DQ. Associations between TNFAIP3 gene polymorphisms and systemic lupus erythematosus risk: an updated meta-analysis. Hla. 2016;88(5):245-52.

25. Kim SK, Choe JY, Bae J, Chae SC, Park DJ, Kwak SG, et al. TNFAIP3 gene polymorphisms associated with differential susceptibility to rheumatoid arthritis and systemic lupus erythematosus in the Korean population. Rheumatology. 2014;53(6):1009-13.

26. Fung E, Smyth DJ, Howson JM, Cooper JD, Walker NM, Stevens H, et al. Analysis of 17 autoimmune disease-associated variants in type 1 diabetes identifies 6q23/TNFAIP3 as a susceptibility locus. Genes Immun. 2009;10(2):188-91.

27. Dieude P, Guedj M, Wipff J, Ruiz B, Riemekasten G, MatucciCerinic M, et al. Association of the TNFAIP3 rs5029939 variant with systemic sclerosis in the European Caucasian population. Ann Rheum. Dis. 2010;69(11):1958-64.

28. Wei P, Yang Y, Guo X, Hei N, Lai S, Assassi S, et al. Identification of an association of TNFAIP3 polymorphisms with matrix metalloproteinase expression in fibroblasts in an integrative study of systemic sclerosis-associated genetic and environmental factors. Arthritis Rheumatol. 2016;68(3):749-60.

29. Song R-h, Yu Z-y, Wang Q, Muhali F-s, Jiang W-j, Xiao L, et al. Polymorphisms of the TNFAIP3 region and Graves' disease. Autoimmunity. 2014;47(7):459-65.

30. Li H, Liu Q, Hou S, Du L, Zhou Q, Zhou Y, et al. TNFAIP3 gene polymorphisms confer risk for Behcet's disease in a Chinese Han population. Hum Genet. 2013;132(3):293-300.

31. Sun F, Li P, Chen H, Wu Z, Xu J, Shen M, et al. Association studies of TNFSF4, TNFAIP3 and FAM167A-BLK polymorphisms with primary Sjogren's syndrome in Han Chinese. J Hum Genet. 2013;58(7):475-9.

32. Zhong H, Li XL, Li M, Hao LX, Chen RW, Xiang K, et al. Replicated associations of TNFAIP3, TNIP1 and ETS1 with systemic lupus erythematosus in a southwestern Chinese population. Arthritis Res Ther. 2011;13(6):R186.

33. Tavares RM, Turer EE, Liu CL, Advincula R, Scapini P, Rhee L, et al. The ubiquitin modifying enzyme A20 restricts B cell survival and prevents autoimmunity. Immunity. 2010;33(2):181-91.

34. Lee YH, Bae SC, Choi SJ, Ji JD, Song GG. Associations between TNFAIP3 gene polymorphisms and rheumatoid arthritis: a metaanalysis. Inflamm Res. 2012;61(6):635-41.

35. Shimane K, Kochi Y, Horita T, Ikari K, Amano H, Hirakata M, et al. The association of a nonsynonymous single-nucleotide polymorphism in TNFAIP3 with systemic lupus erythematosus and rheumatoid arthritis in the Japanese population. Arthritis Rheum. 2010;62(2):5749.

36. Zhang L, Yuan X, Zhou Q, Shi J, Song Z, Quan R, et al Associations between TNFAIP3 gene polymorphisms and rheumatoid arthritis risk: a meta-analysis. Arch Med Res. 2017;48(4):386-92.

37. Han JW, Wang Y, Li HB, Alateng C, Bai YH, Sun ZQ, et al. Single nucleotide polymorphisms of TNFAIP 3 are associated with systemic lupus erythematosus in Han Chinese population. Int J Immunogenet. 2016;43(2):96-100 